\title{
Advanced Cantonese ESL Learners' Use of a Monolingual Dictionary for Language Production
}

\author{
Alice Y.W. Chan, Department of English, City University of Hong Kong, \\ Hong Kong (enalice@cityu.edu.hk)
}

\begin{abstract}
This article reports on the results of a research study which investigated the use of monolingual dictionaries by Hong Kong advanced Cantonese ESL learners in the production of target language sentences. Thirty-one English majors participated in a sentence completion task and a sentence construction task with and without the help of a monolingual dictionary. In the sentence completion task, a full Chinese context and a partial English context were given, whereas in the sentence construction task, only a few English prompts were given. Different self-reporting protocols, including introspective questionnaires, retrospective questionnaires and think-aloud recordings, and a post-task focus-group interview were conducted to tap into the participants' thinking processes during dictionary consultation. The results show that a monolingual dictionary is useful in helping learners produce target language sentences, yet learners encounter different kinds of consultation problems, some of which are related to their general use of dictionaries and others to the language in which their thinking processes are engaged. It is suggested that ESL learners use both monolingual and bilingualized dictionaries in their learning and that ESL teachers design dictionary skills training programs which take into account learners' linguistic competence and actual consultation problems.
\end{abstract}

Keywords: LEXICOGRAPHY, MONOLINGUAL DICTIONARIES, DICTIONARY USE, DICTIONARY CONSULTATION, USEFULNESS OF DICTIONARIES, LANGUAGE PRODUCTION, SENTENCE COMPLETION, SENTENCE CONSTRUCTION, CANTONESE ESL LEARNERS, PROBLEMS ENCOUNTERED, CONTEXTS GIVEN

Opsomming: Gevorderde Kantonese ESL-aanleerders se gebruik van 'n eentalige woordeboek vir taalproduksie. In hierdie artikel word verslag gedoen van die resultate van 'n navorsingstudie wat die gebruik van eentalige woordeboeke deur gevorderde Kantonese ESL-aanleerders in Hong Kong in die produksie van teikentaalsinne ondersoek het. Een-endertig studente met Engels as hoofvak het deelgeneem aan ' $n$ taak waarin hulle sinne moes voltooi en aan ' $n$ taak waarin hulle sinne moes bou met en sonder die hulp van ' $n$ eentalige woordeboek. In die taak waarin hulle sinne moes voltooi, is die volle Chinese konteks en 'n gedeeltelike Engelse konteks verskaf, terwyl daar in die sinsboutaak slegs 'n paar Engelse leidrade gegee is. Verskillende selfrapporteringsprotokolle, insluitende introspektiewe vraelyste, retrospektiewe vraelyste en hardopdinkopnames, asook ' $n$ onderhoud met die fokusgroep nadat die taak afgehandel is, is onderneem om die deelnemers se denkprosesse gedurende die raadpleging van 'n woordeboek te volg. Die resultate toon dat 'n eentalige woordeboek nuttig is om aanleerders te help om teikentaalsinne te produseer, maar aanleerders kom verskillende soorte probleme teë tydens die raadpleging 
van 'n woordeboek, waarvan party verwant is aan die algemene gebruik van woordeboeke, en ander aan die taal waarin gedink word. Daar word voorgestel dat ESL-aanleerders sowel eentalige as verklarende woordeboeke met vertalings gebruik wanneer hulle leer en dat ESL-onderwysers programme ontwikkel wat woordeboekvaardighede oordra en wat leerders se taalvaardigheid in ag neem sowel as hulle werklike raadplegingsprobleme.

Sleutelwoorde: LEKSIKOGRAFIE, EENTALIGE WOORDEBOEKE, WOORDEBOEKGEBRUIK, WOORDEBOEKRAADPLEGING, NUTTIGHEID VAN WOORDEBOEKE, TAALPRODUKSIE, SINSVOLTOOIING, SINSBOU, KANTONESE ESL-AANLEERDERS, PROBLEME TEËGEKOM, KONTEKS VERSKAF

\section{Introduction}

The use of a dictionary is regarded as "an indispensable component of home and academic life" (Abecassis 2007: 249). Although dictionaries contain much useful encoding and decoding information, many learners as a foreign language (FL) or second language (SL) cannot make full use of them in their learning and ignore or misread a lot of useful information (Nesi and Meara 1994). They do not possess the dictionary skills needed, and many of them have not received formal dictionary skills training before (Chan 2005). Even language teachers are not necessarily adequately equipped to provide comprehensive dictionary skills training for their students, and they themselves are not fully aware of the potential advantages of a learner's dictionary in the learning of a second or foreign language (Miller 2008). As a result, language learners encounter various difficulties in their use of dictionaries. Among the common ones are their inability to locate the relevant information needed and their difficulties in identifying, for example, the transitivity of a target verb or the countability of a target noun (Chan 2012b).

The most popular kinds of information learners seek from a learner's dictionary are definitions of words or, in the case of bilingual or bilingualized dictionaries, 1 equivalents in the other language for decoding purposes only (Béjoint 1981; Lew 2004). Many dictionary users do not use a dictionary for guiding them on word usage or encoding. If they want to know the syntactic restrictions, register appropriateness or collocations to be able to use the word appropriately, they tend to resort to grammar books instead (FrankenbergGarcia 2011). Advanced English as a Second Language (ESL) or English as a Foreign Language (EFL) learners use dictionaries also for encoding purposes (Chan 2005), but they still often fail to take advantage of information on grammar and usage, including grammar codes (Chan 2012b; Carduner 2003; Frankenberg-Garcia 2011; Lew and Dziemianko 2006; Summers 1988). Grammatical information in a dictionary is regarded as user-friendly for encoding if it is often consulted and if it results in correct language production (Dziemianko 2006), yet ESL learners most often use examples and definitions in their con- 
sultation of dictionaries rather than explicit grammatical information when they want to determine the correct use of a target word (Chan 2012b; Bogaards and Van der Kloot 2002; Dziemianko 2006, in press), leading to some researchers' claim that grammar codes could be eliminated from pedagogical dictionaries (Bogaards and Van der Kloot 2002). While it is true that examples are helpful not only in explaining meaning but also in showing lexico-grammatical patterns (Cowie 1999b), inappropriate generalisations may sometimes be made regarding the use of target words (Chan 2012b), and learners sometimes misidentify examples and indicating useless ones as helpful (Dziemianko in press).

To understand how well dictionaries assist students, it is necessary to conduct experimental tests in user-based lexicographical research (Battenburg 1991) and to examine how successful a dictionary is in the provision of lexical support learners need when they are engaged in various kinds of second language receptive and productive activities (Swanepoel 2000). Despite the fact that interest in empirical user-studies in lexicography is "on the rise" (Lew 2011a: 1), empirical studies into the use of dictionary information for language production are still relatively scarce. The present research aimed at bridging this research gap by examining ESL learners' use of monolingual dictionaries in language production.

The decision to exclusively focus on monolingual dictionaries was not arbitrary. Although many previous research studies found that learners, including advanced ESL or EFL learners, tend to use bilingual or bilingualized dictionaries (Atkins and Varantola 1997, 1998; Baxter 1980; Lew 2004), recent research has found that many advanced Hong Kong Cantonese ESL learners use both bilingualized and monolingual dictionaries in their work or studies, and some use monolingual dictionaries exclusively instead of relying on both (Chan 2011). Monolingual dictionaries are regarded as excellent models for advanced foreign learners (Cowie 1999a). However, just because all dictionary information is presented in the learner's target language, the design and presentation of these dictionaries often necessitate skills that many learners lack (Kernerman 2007). To learners of the language as a second language, monolingual dictionaries may present even more difficulties, as in the production of target language sentences, many ESL learners tend to think in their mother tongue. L1 transfer has been found to be one major source of learner problems not just among lower proficiency learners, but high-proficiency learners also rely on the syntax and vocabulary of their L1 when writing in L2 and/or when encountering difficulties in the production of target language output (Chan 2004b; Bhela 1999; Van Weijen, Van den Bergh, Rijlaarsdam and Sanders 2009). Given that monolingual dictionaries rely on corpora which do not necessarily provide "the English that is really needed or wanted by its users" (Kernerman 2007: 142), it is interesting to investigate the usefulness of these dictionaries to ESL learners when their target language production processes are guided by their native language and when their production processes are not. 


\section{Objectives}

The objectives of the present study were to (i) explore how advanced ESL learners in Hong Kong used a monolingual dictionary for target language production, (ii) examine the usefulness of a monolingual dictionary for target language production, and (iii) investigate the general problems learners encountered in dictionary consultation as well as those they encountered when different amounts and nature of contexts were given.

\section{Participants}

Thirty-one participants, including eight males and twenty-three females, participated in the study. They were all English majors at a local university. Their ages ranged from 20 to 24: One year 1 student, eleven year 2 students, and nineteen year 3 students. Twenty of them had learnt English for 15-19 years and eleven had learnt English for 20 years or more. In view of their English learning backgrounds, they could all be regarded as advanced ESL learners.

\section{Procedures}

The participants were asked to do a Sentence Completion Task and a Sentence Construction Task with and without the use of a monolingual dictionary.

\section{Sentence Completion Task}

The first part of the Sentence Completion Task was done without the use of a dictionary. It aimed to investigate the participants' prior knowledge of the use of the target words. For each target English word, a sentence context was invented and given in written Chinese. The target words and some parts of the corresponding English sentences were also given (see Appendix A). The participants had to complete the English sentences using the given target words. They were instructed to finish all the questions in this part before they did the second part. Although a Chinese context was given for each sentence, the task was not meant to be a translation one. The provision of the Chinese sentences only gave enough contextual information for the intended use of the target words, and the uncompleted English sentences ensured that the participants would use the desired grammatical patterns in the completion of the sentences.

In the second part of the task, the participants had to complete the sentences again with the help of a monolingual dictionary. They were divided into three groups, with one group using Cambridge Advanced Learner's Dictionary 3rd edition (CALD3), one using Collins COBUILD Advanced Dictionary 6th edition (COBUILD6), and one using Longman Dictionary of Contemporary English 5th edition (LDOCE5). These three dictionaries were chosen because they were, to 
the author's knowledge, among the most popular (paper) monolingual dictionaries used in Hong Kong. ${ }^{2}$ The participants were instructed to consult the dictionaries for the correct usage of the given words and associated expressions, but they were not allowed to change the answer to any of the questions in the first part after doing the second part. Different self-report protocols, namely Think-aloud Recordings (for the LDOCE5 group), an Introspective Questionnaire (for the COBUILD6 group), and an Instant Retrospective Questionnaire (for the CALD3 group) were used to tap into the participants' thinking processes in the course of dictionary consultation.

\section{Sentence Construction Task}

The first part of the Sentence Construction Task was also done without the use of a dictionary to investigate the participants' prior knowledge of the use of the target words. For each sentence, three to four English prompts, one of which being the target word, were given to the participants (see Appendix B). They had to use the given prompts to construct a grammatical and meaningful English sentence, making whatever changes to the prompts deemed necessary but following the order of the prompts. The prompts were given to ensure that the desired grammatical patterns would be followed in the participants' construction of the sentences. They were instructed to finish all the questions in this part before they did the second part.

The second part of the task, which aimed to investigate how the participants used a monolingual dictionary to help them construct English sentences, had the same prompts but the target words were underlined. The participants were required to construct a sentence again by consulting a monolingual dictionary for the correct usage of each of the underlined target words.

The participants were also divided into three groups with different groups using different dictionaries and doing different self-reporting protocols: an introspective questionnaire, a retrospective questionnaire and introspective think-aloud recordings. The LDOCE5 group did the introspective questionnaires, the COBUILD6 group did the retrospective questionnaires, and the CALD3 group did the think-aloud group recordings. The groupings of the participants for this task differed from those for the Sentence Completion Task, so that no participant would use the same dictionary and/or be engaged in the same self-reporting protocol for the two tasks.

Although different dictionaries were used and different protocols were followed by different participants, no attempt was made to compare the effectiveness of the three dictionaries or the performance of the different groups, as the main focus of the study was to uncover learners' problems in extracting dictionary information for language production.

The Sentence Completion Task with the provision of a Chinese context was included because it has often been reported that many Cantonese ESL learners tend to think in Chinese when producing written English output 
(Chan 2004b, 2010). They often have a target Chinese word in mind when constructing an English sentence and attempt to convert it in English and fit it into the Chinese context in mind. On the other hand, the Sentence Construction Task without the involvement of Chinese was included because learners sometimes have a target English word as well as its possible collocations or other associated words in mind and try to fit the target word into the context instead of doing mental translations based on a Chinese equivalent.

\section{Target Words}

The target words used in both the sentence completion and construction tasks were first piloted with nine non-native English majors whose English proficiency and language backgrounds were comparable to those of the participants. For the Sentence Completion task, a total of thirty-two target words, and thus thirty-two Chinese sentence contexts and corresponding uncompleted English sentences, were piloted. For the Sentence Construction Task, a total of thirty target words and their corresponding prompts were piloted. Only the target words which were found to be difficult for about $70 \%$ of the students in the pilot group (i.e. only those which were incorrectly used by about $70 \%$ of the pilot group) without consulting a dictionary were selected for the real tasks.

\section{Sentence Completion Task}

The target words included in the Sentence Completion Task (a total of 10) were all simple English words familiar to advanced ESL learners rather than new or exotic words, but the uses of the words necessitated by the Chinese contexts were mostly unfamiliar to Hong Kong Cantonese ESL learners. ${ }^{3}$ To ensure that the completed English sentences matched the Chinese contexts, the participants had to use the target words correctly with appropriate grammatical associations, such as the correct choice of prepositions, of phrasal verb particles, or verb complementation, etc. The following are some examples of the target words and the associated uncompleted English sentences (see Appendix A for a complete list).

(rush):

(brush):

I don't want to rush into a decision. brushed past me, but he didn't see me.

\section{Sentence Construction Task}

The target words included in the Sentence Construction Task (also 10) were also simple English words familiar to advanced ESL learners, but they were all found to be very commonly misused by Hong Kong Cantonese ESL learners (Bunton 1989, 1994; Heaton and Turton 1987; Jenkins 1990). The grammatical 
patterns focused on included the choice of prepositions for a target noun, the choice of prepositions after a target verb, and the use of a verb in a correct transitivity pattern, etc. The following are some examples of the target words and the corresponding prompts (see Appendix B for a complete list).

(knowledge): (little) (knowledge) (linguistics)

(assist): $\quad$ (he) (assist) (murder) (her husband)

\section{Self-Reporting Protocols}

Both retrospective and introspective self-reporting protocols were used in the dictionary consultation tasks for tapping into the participants' thinking processes during dictionary consultation and for gathering their evaluation of the effectiveness of dictionary information. Since delayed retrospective reports are criticized as being based on participants' memory (Kaivanpanah and Alavi 2008), and narration of what they think they have done after completing a task "may only have a tenuous relationship to the original attended information" (Kasper 2000: 336) and may not relate clearly to any specific observable behavior (Ericsson and Simon 1993), introspective questionnaires were also used in the study to minimize the distortion of information or the effects of participants' having forgotten the information. Introspective think-aloud protocols were used alongside introspective questionnaires to elicit "a real-time process of cognitive activities" (Tono 2001: 68) and to allow learners to process information simultaneously with introspection.

\section{Introspective Questionnaires}

The participants in the Introspective Questionnaire groups were required to do a questionnaire immediately after finishing each question in Part II of the respective task. The questionnaires aimed at eliciting their instant and detailed feedback on the way a certain dictionary entry helped them complete or construct a target sentence. They had to report on their feelings when they ended a search (e.g. sure that the decision was correct, not sure whether the decision was correct, sure that they didn't get the right information) and to specify the part(s) of the dictionary entries which they found the information they wanted to look for. These appeared in the questionnaires as forced-choice questions. The participants also had to write out the examples/definitions or other dictionary information they used to make a final decision, to demonstrate how the information showed that their decisions were correct, to account for the reason(s) why they were doubtful about their decisions, to report on the difficulties, if any, they encountered, and so on. These all appeared in the questionnaires as open-ended questions. All the questions were given in written English and all the participants responded in written English. ${ }^{4}$ 
Introspective Think-aloud Recordings

The participants in the Think-aloud groups recorded the whole of their decision-making processes during dictionary consultation using whatever language they were comfortable with in a sound-proof room. The whole process of searching for the appropriate examples, definitions and/or other dictionary information, determining what dictionary information should be used, and choosing the appropriate dictionary information to guide them to the completion and construction of a target sentence, etc was recorded. Three students doing the Sentence Construction Task chose to speak entirely in English, and the rest (doing either task) chose to speak mainly in a mixed-code of English and Cantonese. The recordings were made using an audio recorder called Audacity and converted into wave sound files. A research assistant transcribed all the sound files for analysis and the researcher (i.e. the author) translated the Cantonese utterances into English.

\section{Instant Retrospective Questionnaires}

The participants in the instant Retrospective Questionnaire group completed a retrospective questionnaire immediately after finishing the whole task. The questionnaire aimed at investigating the participants' overall assessment of their performance in Part II of the respective task and their general evaluation of the usefulness of the dictionary or the different parts of the entries. They had to identify the information they consulted most, indicate from which part of the dictionary entries they found the answers to most of the questions, comment on the usefulness of the different parts of the dictionary entries in general, evaluate the overall usefulness of the dictionary, specify the frequency with which they encountered difficulties, estimate the extent to which they thought their own uses of the target words were changed after the consultation task, and so on. All the questions were given as forced-choice questions in written English and all the participants responded in written English.

\section{Post-Task Focus Group Interview}

A Post-task Focus Group Interview lasting about an hour was conducted within a month of the completion of the two tasks by all the participants. Six students participated in the interview, including one male and five females who used different dictionaries and who were engaged in different selfreporting protocols in the two tasks. Copies of all the dictionaries used and copies of all the task sheets completed by the interviewees were brought by the interviewer to the interviews to refresh the interviewees' memory of their dictionary consultation and decision-making processes and to enable them to quote precise information from the dictionaries. Before the commencement of 
the interview, the interviewer gave clear instructions on the expectations of the interview in a mixed code of English and Cantonese. She was then responsible for asking prompting questions centring around the difficulties that the participants encountered, the strategies they used to overcome the difficulties, the part(s) of the dictionary entries they found most useful, the way the information helped them make a decision, and their own use of the target items after dictionary consultation. The reasons underlying their responses were also discussed. All the interviewees spoke in Cantonese except when quoting dictionary examples, dictionary definitions, and/or task-related prompts or contexts. The proceedings of the interviews were recorded using both a video camera and a mini-disk recorder. The interviewer transcribed the whole proceedings of the interview and the researcher translated the Cantonese utterances into English.

\section{Results}

\section{Performance of Students and Performance on Target Words}

The following section will give a summary of the participants' performance in the sentence completion and construction tasks with and without the use of a dictionary. Their performance will be presented as accuracy rates. A sentence was deemed accurately completed (in the Sentence Completion Task) when the target word was used with the appropriate grammatical associations (e.g. a correct preposition) and the resultant meaning of the sentence was consistent with the Chinese context. A sentence was regarded as accurately constructed (in the Sentence Construction Task) when the target word was used with the appropriate grammatical associations (e.g. correct transitivity pattern) with the corresponding prompts. Irrelevant grammatical mistakes, such as subject-verb agreement, were not taken into account.

\section{Sentence Completion Task}

\section{WITHOUT THE USE OF A DICTIONARY}

Of the ten words included for investigation, only three words despair, rush and substitute received an accuracy rate of $30 \%$ or above. The rest $(70 \%)$ received an accuracy rate of $20 \%$ or below. Only six students $(19.4 \%)$ from the three groups could accurately complete four or more sentences ( $40 \%$ or more). Twenty students $(64.5 \%)$ could accurately complete only one or two sentences or even none $(0 \%-20 \%)$ (See Tables 1 and 2$)$.

\section{WITH THE USE OF A DICTIONARY}

Nine sentences $(90 \%)$ were accurately completed by over half $(50 \%)$ of the participants. Six sentences $(60 \%)$ were accurately completed by $80 \%$ or more of the 
participants. The words which received the highest accuracy rates were rush and brush (both 93.5\%), which showed big leaps from their originals of $48.4 \%$ and $16.1 \%$. The word limit received the lowest accuracy rate of $48.4 \%$. Only fifteen students (48.4\%) could accurately complete the sentence with the use of a dictionary. Twenty students $(64.5 \%)$ could accurately complete eight or more sentences $(80 \%$ or more). However, still one student $(3.2 \%)$ could accurately complete only three sentences or less (30\% or less) (See Tables 1 and 2). A paired, two-tailed t-test using Excel 2010 showed that the difference between the participants' overall sentence completion performance without using a dictionary and that using a dictionary was statistically significant at the 0.05 significance level $(t=-7.84, p=0.000259)$.

Table 1: The accuracy rate of each target word in the Sentence Completion Task with and without the use of a dictionary

\begin{tabular}{|l|c|c|}
\hline \multirow{2}{*}{ Target Word } & \multicolumn{2}{|c|}{$\begin{array}{c}\text { Percentage of participants who could complete the } \\
\text { sentences accurately }\end{array}$} \\
\cline { 2 - 3 } & Without a dictionary (N=31) & With a dictionary (N=31) \\
\hline Rush & $48.4 \%$ & $93.5 \%$ \\
\hline Charge & $19.4 \%$ & $83.9 \%$ \\
\hline Brush & $16.1 \%$ & $93.5 \%$ \\
\hline Frighten & $19.4 \%$ & $80.6 \%$ \\
\hline Deceive & $9.7 \%$ & $58.1 \%$ \\
\hline Limit & $19.4 \%$ & $48.4 \%$ \\
\hline Substitute & $45.2 \%$ & $58.1 \%$ \\
\hline Monument & $0 \%$ & $67.7 \%$ \\
\hline Improve & $6.5 \%$ & $90.3 \%$ \\
\hline Despair & $35.5 \%$ & $83.9 \%$ \\
\hline Total & $21.9 \%(68 / 310)$ & $75.8 \%(235 / 310)$ \\
\hline
\end{tabular}

Table 2: Individual participants' performance on the Sentence Completion task with and without the use of a dictionary

\begin{tabular}{|l|c|c|}
\hline \multirow{2}{*}{ Student } & \multicolumn{2}{|c|}{ Percentage of sentences accurately completed } \\
\cline { 2 - 3 } & Without a dictionary (N=10) & With a dictionary (N=10) \\
\hline Student 1 & $10 \%$ & $70 \%$ \\
\hline Student 2 & $30 \%$ & $80 \%$ \\
\hline Student 3 & $60 \%$ & $60 \%$ \\
\hline Student 4 & $10 \%$ & $80 \%$ \\
\hline Student 5 & $10 \%$ & $70 \%$ \\
\hline
\end{tabular}




\begin{tabular}{|c|c|c|}
\hline Student 6 & $10 \%$ & $80 \%$ \\
\hline Student 7 & $0 \%$ & $80 \%$ \\
\hline Student 8 & $20 \%$ & $90 \%$ \\
\hline Student 9 & $0 \%$ & $70 \%$ \\
\hline Student 10 & $10 \%$ & $50 \%$ \\
\hline Student 11 & $40 \%$ & $90 \%$ \\
\hline Student 12 & $30 \%$ & $90 \%$ \\
\hline Student 13 & $50 \%$ & $90 \%$ \\
\hline Student 14 & $0 \%$ & $90 \%$ \\
\hline Student 15 & $20 \%$ & $80 \%$ \\
\hline Student 16 & $10 \%$ & $30 \%$ \\
\hline Student 17 & $20 \%$ & $80 \%$ \\
\hline Student 18 & $20 \%$ & $90 \%$ \\
\hline Student 19 & $20 \%$ & $80 \%$ \\
\hline Student 20 & $20 \%$ & $80 \%$ \\
\hline Student 21 & $10 \%$ & $90 \%$ \\
\hline Student 22 & $0 \%$ & $40 \%$ \\
\hline Student 23 & $40 \%$ & $70 \%$ \\
\hline Student 24 & $20 \%$ & $80 \%$ \\
\hline Student 25 & $60 \%$ & $100 \%$ \\
\hline Student 26 & $30 \%$ & $80 \%$ \\
\hline Student 27 & $40 \%$ & $70 \%$ \\
\hline Student 28 & $10 \%$ & $80 \%$ \\
\hline Student 29 & $20 \%$ & $60 \%$ \\
\hline Student 30 & $30 \%$ & $80 \%$ \\
\hline Student 31 & $30 \%$ & $70 \%$ \\
\hline Total & $21.9 \%(68 / 310)$ & $75.8 \%(235 / 310)$ \\
\hline
\end{tabular}

\section{Sentence Construction Task}

\section{WITHOUT THE USE OF A DICTIONARY}

Of the ten words included for investigation, only three words (30\%) knowledge, comprise and assist received an accuracy rate of over 50\%. Two words (20\%), opposite and anticipate received an accuracy rate of $30 \%$ or below. Only nine students $(29 \%)$ from the three groups could accurately construct five or more sentences $(50 \%$ or more) correctly. Eleven students $(35.5 \%)$ could accurately construct only three sentences or even less (30\% or less) (See Tables 3 and 4 ). 


\section{WITH THE USE OF A DICTIONARY}

Seven sentences $(70 \%)$ were accurately constructed by $80 \%$ or more of the participants. The words which received the highest accuracy rates was knowledge $(100 \%)$, but its original accuracy rate without the use of a dictionary was also quite high $(61.3 \%)$. The word guilty received the lowest accuracy rate of $45.2 \%$. Only fourteen students $(45.2 \%)$ could accurately construct the sentence even with the use of a dictionary. Twenty students $(64.5 \%)$ could accurately construct eight or more sentences ( $80 \%$ or more). However, still three students $(9.7 \%)$ could only accurately construct five sentences or less (50\% or less) (see Tables 3 and 4). A paired, two-tailed t-test using Excel 2010 showed that the difference between the participants' overall sentence construction performance without using a dictionary and that using a dictionary was statistically significant at the 0.05 significance level $(t=-6.76, p=0.0000827)$.

Table 3: The accuracy rate of each target word in the Sentence Construction Task with and without the use of a dictionary

\begin{tabular}{|l|c|c|}
\hline \multirow{2}{*}{ Target Word } & \multicolumn{2}{|c|}{$\begin{array}{c}\text { Percentage of participants who could construct the } \\
\text { sentences accurately }\end{array}$} \\
\cline { 2 - 3 } & Without a dictionary (N=31) & With a dictionary (N=31) \\
\hline Knowledge & $61.3 \%$ & $100 \%$ \\
\hline Reason & $32.3 \%$ & $61.3 \%$ \\
\hline Comprise & $61.3 \%$ & $90.3 \%$ \\
\hline Opposite & $3.2 \%$ & $67.7 \%$ \\
\hline Guilty & $41.9 \%$ & $45.2 \%$ \\
\hline Cure & $32.3 \%$ & $80.6 \%$ \\
\hline Anticipate & $25.8 \%$ & $80.6 \%$ \\
\hline Inform & $48.4 \%$ & $90.3 \%$ \\
\hline Befriend & $35.5 \%$ & $87.1 \%$ \\
\hline Assist & $61.3 \%$ & $83.9 \%$ \\
\hline Total & $40.3 \%(125 / 310)$ & $78.7 \%(244 / 310)$ \\
\hline
\end{tabular}

Table 4: Individual participants' performance on the Sentence Construction Task with and without the use of a dictionary

\begin{tabular}{|l|c|c|}
\hline \multirow{2}{*}{ Student } & \multicolumn{2}{|c|}{ Percentage of sentences accurately constructed } \\
\cline { 2 - 3 } & Without a dictionary $(\mathrm{N}=10)$ & With a dictionary $(\mathrm{N}=10)$ \\
\hline Student 1 & $50 \%$ & $90 \%$ \\
\hline Student 2 & $50 \%$ & $80 \%$ \\
\hline Student 3 & $40 \%$ & $80 \%$ \\
\hline
\end{tabular}




\begin{tabular}{|l|c|c|}
\hline Student 4 & $30 \%$ & $80 \%$ \\
\hline Student 5 & $60 \%$ & $100 \%$ \\
\hline Student 6 & $70 \%$ & $80 \%$ \\
\hline Student 7 & $40 \%$ & $70 \%$ \\
\hline Student 8 & $20 \%$ & $90 \%$ \\
\hline Student 9 & $30 \%$ & $100 \%$ \\
\hline Student 10 & $40 \%$ & $80 \%$ \\
\hline Student 11 & $20 \%$ & $80 \%$ \\
\hline Student 12 & $50 \%$ & $70 \%$ \\
\hline Student 13 & $80 \%$ & $90 \%$ \\
\hline Student 14 & $30 \%$ & $70 \%$ \\
\hline Student 15 & $30 \%$ & $100 \%$ \\
\hline Student 16 & $40 \%$ & $90 \%$ \\
\hline Student 17 & $40 \%$ & $40 \%$ \\
\hline Student 18 & $10 \%$ & $90 \%$ \\
\hline Student 19 & $40 \%$ & $90 \%$ \\
\hline Student 20 & $40 \%$ & $70 \%$ \\
\hline Student 21 & $30 \%$ & $50 \%$ \\
\hline Student 22 & $60 \%$ & $70 \%$ \\
\hline Student 23 & $30 \%$ & $80 \%$ \\
\hline Student 24 & $60 \%$ & $60 \%$ \\
\hline Student 25 & $40 \%$ & $90 \%$ \\
\hline Student 26 & $20 \%$ & $50 \%$ \\
\hline Student 27 & $40 \%$ & $700 \%$ \\
\hline Student 28 & $30 \%$ & $80 \%$ \\
\hline Student 29 & $40 \%$ & $70 \%$ \\
\hline Student 30 & $40 \%$ & $7244 / 310)$ \\
\hline Student 31 & $50 \%$ & \\
\hline Total & $(125 / 310)$ & $80 \%$ \\
\hline
\end{tabular}

\section{Perception of Usefulness of Dictionary Information}

\section{Sentence Completion Task}

For the retrospective questionnaire group, $36.4 \%$ of the participants $(N=11)$ thought that the definitions were extremely useful and $90.9 \%$ thought that the examples were extremely useful. $45.5 \%$ regarded the special features and the explanations as extremely or very useful. The most prevalent difficulty encoun- 
tered by the retrospective group was that there were too many definitions and examples $(27.3 \%)$. Nobody thought that the codes or abbreviations were difficult to understand, that there were no special features to attract their attention, that they could not find the information about word classes, or that the word was missing. On the whole, $81.8 \%$ of the participants thought that the dictionaries used were extremely or very useful. $27.3 \%$ thought that they had a lot of improvements in the use of the target words after the dictionary consultation whereas the rest thought that they made some improvements. $54.5 \%$ of them were confident that $76 \%-99 \%$ of the target words were constructed correctly after the use of a dictionary. $72.7 \%$ thought that it was extremely or very important to have more examples included.

As for the introspective group, $84 \%(\mathrm{~N}=100)$ (10 participants x 10 consultations) of the decisions were made after the participants had consulted the definitions, and $64 \%$ made after the participants had consulted the examples. The word for which most participants were sure that their decisions were correct was frighten $(90 \%)$, and the words which the least number of participants $(40 \%)$ were confident about were limit and monument.

\section{Sentence Construction Task}

For the retrospective questionnaire group, $50 \%$ of the participants $(\mathrm{N}=10)$ thought that the definitions were extremely useful and $90 \%$ thought that the examples were extremely useful. $30 \%$ regarded the special features as extremely or very useful. The most prevalent difficulty encountered by the retrospective group was that there were too many definitions and examples (50\%). Nobody thought that the codes or abbreviations were difficult to understand and only one participant $(10 \%)$ thought that the usage information was not clear or that the word was missing. On the whole, $80 \%$ of the participants thought that the dictionaries were extremely or very useful. $50 \%$ thought that they had a lot of improvements in the use of the target words after the dictionary consultation whereas the rest thought that they made some improvements. $90 \%$ of them were confident that $76 \%-99 \%$ of the target words were constructed correctly after the use of a dictionary. $90 \%$ thought that it was extremely or very important to have more examples included, and $50 \%$ thought that the definitions should be made clear and that more information on the word class of a word should be given.

As for the introspective group, $90 \%(\mathrm{~N}=110)$ (11 participants $x 10$ consultations) of the decisions were made after the participants had consulted the examples, $44.5 \%$ made after the participants consulted the special features, and $43.6 \%$ made after the participants consulted the definitions. The words for which most participants were sure that their decisions were correct were knowledge and befriend $(90.9 \%)$, and the word which the least number of participants $(72.7 \%)$ were confident about was reason. ${ }^{5}$ 


\section{L2 Language Production with the Use of a Monolingual Dictionary}

Although the use of dictionaries resulted in the participants' significant improvements in language production, some participants encountered certain difficulties and made incorrect judgment. In this section, the problems that they encountered will be examined by scrutinizing their introspective written reports, think-aloud verbal reports and post-task interview reports. The provision of different amounts of contexts in the two tasks will also be taken into account. $^{6}$

Learner Problems Unique to Language Production with a Full Context in the Native Language

With the provision of a full Chinese context in the Sentence Completion Task, some participants had the tendency to compare the meaning of a target English word with the meaning of the corresponding Chinese expression given in the Chinese context. The amount of correspondence between the two was regarded as very important, and the participants only felt secure when there was an exact match. When no exact match could be found or when the given dictionary meaning had different connotations from the Chinese context, they became daunted. For example, when consulting the entry frighten in completing the sentence The high prices many customers (see Appendix A), Student 4 compared the definition "If you frighten away a person or animal or frighten them off, you make them afraid so that they go away or stay some distance away from you (COBUILD6)" with the Chinese expression 卻步 (frighten off) literally. He could not decide if the definition could be used as the basis for the completion of the sentence because of his uncertainty about the physical actions involved in the Chinese context. ${ }^{7}$

I am not sure about 卻步, whether it means physically away from or just feel afraid, anxious or nervous. (Student 4)

Similarly, the amount of physical contact involved was a major determining factor in the completion of the sentence with the word brush (see Appendix A). Some participants were concerned about the amount of physical contact invoked by the given Chinese expression 擦身而過 (brush past) and based their decisions on their own personal experience and expectations of its use. The definitions of the English word brush were, therefore, taken very literally, and comparisons were deliberately made between the amounts of physical contact necessitated by the Chinese expression and the definitions of the English word. The following quotes from the focus-group interview show the participants' deliberate comparisons:

But it says here one thing brushes against another, or if you brush one thing against another, the first thing touches the second thing slightly while passing it, so it matches 
the Chinese expression 擦身而過... That is, when they walked past each other they touched each other slightly. (Student 5)

My understanding is that 擦身而過 does not involve any physical contact. (Student 1)

But they touch slightly, so this means that there is really physical contact. (Student 22)

Learners sometimes could not make appropriate deductions from a dictionary definition which had different wording from the given Chinese context and tended to look for unnecessary correspondence. For example, some participants were concerned with the collocation of the word publicly with the target word charge when seeing the former in one of the definitions of the latter: "When the police charge someone, they formally accuse them of having done something illegal.... If you charge somebody with doing something wrong or unpleasant, you publicly say that they have done it." (COBUILD6, emphasis added). Therefore, they were again unsure of the appropriateness of the definition as a model for sentence completion, as the corresponding meaning of publicly was not shown in the Chinese context, e.g.:

I am not sure if the accusing is done 'publicly'. (Student 6)

Words which involved two constituents the order of which was significant to the meaning of the resultant sentences also caused difficulty in making a decision. For example, the dictionary definition and/or examples for the target word substitute did not have a clear indication of the order of the constituents. Some participants could not identify from the given information what the replacing element was and what the replaced element was, so they were not sure if the order of constituents given in the dictionary entry was consistent with the order of the corresponding constituents given in the Chinese context, e.g.:

So what is what, what substitutes for what? ... It should be the one in front replacing the one that comes after, ... but what substitutes for what? ... I am not sure. (Student 12)

Learner Problems Unique to Language Production with a Partial Context in the Target Language

Without a full context in the native language, the cognitive demands required by the Sentence Construction Task with target language prompts resulted in different learning problems.

Because the participants could add any constituent in the construction of a sentence, some of them partially followed the information given in the dictionaries but added intervening constituents which altered the desired sentence 
structure. For example, some learners added you after the target word reason (prompts given: what - reason - reject - proposal) and constructed sentences like What is the reason for you to reject the proposal, correctly taking the preposition for as the complement of reason but ignoring the fact that the preposition was supposed to take an -ing complement (i.e. reason for doing something) rather than a to-infinitive complement with an intervening nominal constituent:

The correct preposition to use after reason is for, so what is the reason for you to reject his proposal. (Student 16)

The ability to distinguish the desired meaning of a target word from its other meanings inconsistent with the given context was also an issue. For example, some participants used reason to VERB as a model structure for the target word reason and constructed sentences such as What is the reason to reject the proposal without noticing that reason in reason to VERB had a meaning subtly different from reason in the given context:

Let me see... The police have reason to believe that he is guilty, then I can use this one, reason to, yes, this to believe that he is guilty is an action because of a reason, the reason makes him do that. (Student 14)

(Reason) To do sth in dictionary matches to reject the proposal in my sentence. (Student 11)

Some of the given prompts which appeared in a dictionary entry in another form were sometimes followed indiscriminately. In the dictionary definition below, the prompt illness was used as part of the post-modifier of someone in someone with an illness. Some participants followed the pattern literally and constructed "The doctor cures him with his illness" without being aware of the incompatibility of using a post-modifier after the pronoun him.

The word cure means make well. To make someone with an illness healthy again, so my sentence is The doctor cures him with his illness, because it means someone with an illness healthy again, and form the sentence it means the doctor will help the patient with his illness. (Student 21)

There were cases in which the participants did not know the word class that a certain target word (e.g. opposite; prompts given: go to - restaurant - opposite cinema) should belong to in the given partial context. Errors in determining which correct example to rely on occurred when the word class judgment was wrong, e.g.:

Opposite... Opposite can be an adjective... can be a preposition..... If opposite is an adjective, then it is possible to have to after it, because there is an example They're completely opposite to each other in every way. After reading I don't think it is a noun. It shouldn't be an adverb either. Then I need to decide whether it is an adjective or a preposition. Here, opposite should be an adjective. It looks 
more like an adjective, so I will use opposite to. (Student 20)

\section{General Learner Problems Not Resulting from Amount and Nature of Contexts Given}

Learner problems irrespective of the amount and nature of contexts given could also be identified. These could be regarded as problems directly related to the use of a dictionary.

Some participants used the syntactic structure of a synonym as a model for language production despite the presence of conflicting dictionary information. A case in point was the use of the word comprise in the Sentence Construction Task (prompts given: class - comprise - only French students). The word was regarded as having the same syntactic requirement of its synonym consist of. Although there were examples showing the use of comprise without the preposition of or its coexistence with of in a different structure, some participants used the structure of the synonym to confirm their (mis)judgment, e.g.:

The course comprises a class book, a practice book and an audio tape. This class is comprised mainly of Italian and French students. Italian students comprise $60 \%$ of the class. Then this word should really be of similar meaning to consist of. So let me see. If so, then the sentence should be The class comprises of only French students, i.e. actually it is quite like The class consists of only French students (Student 14).

An expected answer in mind or a previously known usage might override dictionary examples or definitions. Some participants were very adamant about finding information associated with the grammatical patterns which were consistent with their previous knowledge and followed their preconceptions irrespective of what they read from the dictionaries, apparently becoming "blind" to the presence of appropriate examples or definitions, e.g.:

A limit of is the expected answer in my mind. (Student 1)

The example ... is The class is comprised mainly of Italian and French students. Because there is only this example, I will still use This class comprises of only French students (Student 20)

Comprise is a verb. ... Comprise a class. The course comprises a class. ... Why is of not used ... Italian students comprise $60 \%$ of the class. Actually it should be used with of. This is a formal use. So it should be The class comprises of only French students. (Student 22)

A dictionary headword often contained examples and definitions used in different grammatical patterns with very similar meanings, the subtle differences of which were too small for learners to differentiate. Sometimes a decision was made purely by guessing. Examples included the different complementation patterns of rush, such as "rush into, rush to, rush through" and of the word frighten, such as "frighten off, frighten away": 
There are many explanations for $r u s h$. Let me see.... Oh, they are so similar. Let me see. What's the difference? I think there should be no difference. (Student 19)

Why are they so similar? ... Should this be away or off?... I think it should be off. Why do I think so? I just guess. (Student 19)

In the dictionary I can find that the word frighten means to make someone feel afraid, scared, and you can also use frighten somebody, something off, that is to make a person or animal so afraid that they go away and do not do something they were going to do. I think the word off is optional. I can simply omit it. (Student 20)

I do not know if I should add into after the word deceive. There is another example in the dictionary with the use of into after deceive, and I cannot spot the differences between the two. (Student 9)

The grouping of different grammatical patterns under the same definition also created problems. In LDOCE5, brush + against and brush + past were grouped together under the definition touch slightly. An overall definition was given first, followed by an example of the former pattern and an example of the latter. Some participants mistook the definition as applicable only to the first pattern, e.g.:

Touch slightly,... to touch someone or something slightly when passing them.... There is an example here..... But this example Neil brushed past him in the doorway. There is no explanation before it. There is suddenly this example.... That's so strange, I am not sure. (Student 13)

Some other problems related to the layout of an entry were also identified. The use of superscripts in LDOCE5 to differentiate words used in different word classes was not salient enough to attract learners' attention. Some learners had wasted much time searching for information of the word used in a different word class, e.g.:

I saw it. I was stupid. After the word charge ${ }^{1}$ there is a very small word $n$. This shows that it is for the use of noun. When I turned over to the next page, I found charge $^{2}$. After charge ${ }^{2}$, there is a very small word showing $v$. That means verb. ... OK, I have wasted a lot of time. (Student 13)

\section{Discussion and Implications}

In the foregoing sections, the qualitative and quantitative data obtained from the study have been presented. Some general insights into the usefulness of dictionary information and learners' use of dictionaries will be given in this section, followed by some specific insights into learners' dictionary use in the light of the amount and nature of contexts provided by the two dictionary con- 
sultation tasks.

\section{General Usefulness of Dictionary Information in Target Language Production}

As can be seen from the improvements shown in the participants' performance in the second parts of the tasks, dictionary information is, to a certain extent, useful in guiding advanced ESL learners to determine the correct usage of a target word in language production. However, even when learners are engaged in language production when usage is the main concern, they do not pay enough attention to explicit grammatical information, such as grammar codes, which summarize the syntactic patterns of a target word. Instead, they rely on examples for the relevant information for language production and deduce the complementation requirements or other grammatical colligation of a target word from the structural patterns shown in the examples.

Learners' use of examples as sample models for language production is, however, often constrained by their dictionary skills and grammatical competence. In line with Dziemianko (in press)'s findings, many learners have difficulties in identifying the correct example from the many given examples and in choosing the corresponding structural pattern. The usage of words which can be used in different grammatical patterns and which invites numerous dictionary definitions and examples is most difficult to identify, as the presentation of the information may be user-unfriendly, and the definitions and/or examples listed may not show the subtle differences between the different usages. Learners' own preconceptions of word usage may also affect their interpretation of examples, and dictionary information seems to be helpful in giving confirmation to learners on their previous knowledge of the usage of a certain word rather than in providing new knowledge. When a certain usage is unfamiliar to learners, or when learners' preconceptions of the uses of a target word deviate from the normative structures, their preconceptions often override the information given in a dictionary entry and result in wrong decisions.

Another common problem is learners' reliance on the grammatical patterns of the synonyms of a target word. As observed in Chan (2012b), ESL learners may fall into the pitfall of incorrectly using the grammatical patterns of a synonym to deduce the usage of a target English word. The results of the present study also suggest that attempts to use a semantically-related word to deduce the syntactic use of a target word often lead to inaccuracies. Many inaccurate target language constructions can actually be seen as the results of influence caused by the syntactic patterns of a word's synonyms, especially when learners take such patterns to reinforce their misconceptions of the usage of the target word. When encountering a seemingly "similar" syntactic pattern, they become blind to the subtle differences between the usage of the target word and its synonyms or to the presence of a dictionary example which suggests an alternative pattern. 
Usefulness of Dictionary Information when Learners' Thinking Processes are Led by their Mother Tongue

It is evident from the results of the study that the usefulness of dictionary information is sometimes constrained by the language in which learners' thinking processes are engaged. When learners formulate a thought in a foreign or second language, the word which would most probably come to their minds is the L1 word rather than the target language word that is needed (Laufer and Levitzky-Aviad 2006). An exact match between the meanings of the L1 and L2 words is often sought, so a mismatch in the meanings, albeit slight, may lead to difficulty. Some idiomatic expressions in a learner's native language (e.g. 擦身而過 used in Sentence (3) of the Sentence Completion Task (See Appendix A), which literally means touching the body when passing by), may not have an exact L2 translational equivalent which matches the literal meaning (i.e. touching the body). Monolingual dictionaries, which provide definitions only in one language, will not cater for the possible idiomatic meanings that translations in another language may have, especially when the definitions are meant to give the core meanings of the expressions rather than any associated implied meanings. Even after searching the whole dictionary entry, dictionary users who think in their mother tongue may still be daunted by the "imprecise" information given, thinking that the dictionary entry does not provide the English that they really need or want (Kernerman 2007).

Another problem that often arises from learners' attempts to use an L2 equivalent for an L1 word in mind is their exclusive focus on the meaning of the equivalent and their ignorance of the different structural requirements in the two languages. It is well-known that a pair of L1 and L2 equivalents do not necessary share the same structures, such as having different transitivity patterns for verbs (e.g. The verb participate is intransitive in English but its translation in Chinese 參加 is transitive) or different countability for nouns (e.g. English nouns can be countable, uncountable or both, whereas Chinese nouns are not distinguished in number) (Chan: 2004a). The order of constituents associated with a certain word may also differ in different languages. While the word substitute (used in Sentence (7) in the Sentence Completion Task (see Appendix A)) requires the same order or constituents (substitute $A$ for $B$ ) as its Chinese equivalent 代替 $(A$ 代替 $B)$, its synonym replace, which is a more common word familiar to most Cantonese ESL learners, requires a different order (replace $B$ with/by $A$ ). Such similarities or differences in the syntactic requirements of different target vocabulary items and a certain native vocabulary item will of course not be revealed in a monolingual dictionary entry. Learners' previous knowledge of the target and native languages may intervene with their interpretation of dictionary information or even override the given information, resulting in indetermination or inaccuracy. 
Usefulness of Dictionary Information when Learners' Thinking Processes are not Constrained by their Mother Tongue

When learners have in mind a partial context which is entirely in the target language, their familiarity with a word may still be too shallow to enable them to manipulate it appropriately in the context. One obvious problem is their inability to determine the word class of the target word, leading to inappropriate selection of and/or reliance on unacceptable grammatical patterns given in a dictionary entry. Some English words may have comparable contexts when they belong to different word classes. For example, the word opposite used in Sentence (4) of the Sentence Construction Task (see Appendix B) can have the pattern Subject + Linking Verb + opposite (to) + Noun/Noun Phrase when it is used as an adjective (e.g. They are opposite to each other in every way) and as a preposition (e.g. The bank is opposite the supermarket). The only difference between the two is the acceptability of a following preposition to when the word is used as an adjective. Dictionary definitions, examples or even grammar codes showing such a grammatical pattern could not help learners determine which word class the word should belong to when it is used in the context that the learners have in mind. To a certain extent, the dictionary information which learners base their inappropriate decisions on may even reinforce their common errors rather than help them use a word accurately.

Another problem associated with the use of dictionary information for language production with a partial context in the target language is learners' distortion of the normative sentence structure to accommodate the context. They tend to ignore the syntactic requirements of a target word by extracting or adding a certain constituent or part of a constituent and fit it into an alternative structure. The use of with an illness after cure (i.e. cure him with his illness) upon seeing someone with an illness, as well as the adding of the constituent you after reason for (i.e. the reason for you to reject the proposal), is a good illustration. Extracting the correct constituents from a dictionary example or definition and fitting it into a correct context requires a certain level of grammatical competence, without which learners will not be able to process the language successfully. If they cannot identify the subtle differences between the use of a constituent in a dictionary entry and their use of the constituent in their "derived" structure, misapplications of dictionary information will result. Such misapplications are surely not what lexicographers intend to see, but they are exactly the kinds of problems which learners often encounter in their learning of a second or foreign language.

\section{Implications}

The findings of the present research enlighten lexicographers about the actual difficulties ESL learners have in their use of monolingual dictionaries for target language production. It can be seen that because of the use of only one lan- 
guage (learners' target language) in monolingual dictionaries, learners' language proficiency can become a main obstacle to their extraction and application of relevant information even if their thinking processes are not led by their mother tongue. This seems a paradox, because learners attempt to solve their language problems by consulting a resource which requires certain linguistic competence. In this connection, dictionary skills are of vital importance. "In order to benefit from the achievements of modern lexicography, dictionary users need to be trained how to use the dictionary to solve actual typical problems and questions" (Lew 2011a: 3). Not many students are equipped with the necessary skills which enable them to use a dictionary to the fullest extent, nor are they adequately informed of the bank of information they can get from a dictionary. ESL teachers are advised to design dictionary skills training targeting not just basic skills but also the assimilation of dictionary information and the application of such information to their authentic learning contexts. These training programs should also take into account learners' linguistic competence and their actual consultation problems, such as their misuse of the syntactic requirements of a synonym for the usage of a target word and their ignorance of dictionary information as a result of their preconceptions of target word usage.

ESL learners are advised to use multiple resources in their learning. Using both monolingual dictionaries and bilingualized dictionaries, which systematically take care of the learners' native language (Adamska-Sałaciak 2010), should be a good alternative in learners' paths towards complete mastery of a second language. Learners' mistaken beliefs about the alleged lack of definitions and usage information in bilingualized dictionaries should be dispelled (Chan 2010). They should not just focus on L1 equivalents but should supplement L1 definitions and examples with target language definitions and examples and use either to resolve the ambiguity that might arise from the adoption of usage information provided in the other language.

Dictionary compilers should be aware that many details of a dictionary entry may escape learners' attention, so more highlighting techniques or special features should be used. Extra columns or usage boxes showing subtle differences between certain usages (e.g. opposite used as an adjective and as a preposition) may help guide learners' choice of appropriate dictionary information.

\section{Limitations}

Notwithstanding the insights discussed above, the nature of the dictionary consultation tasks may have limited the generalizability of the study. The Sentence Completion Task, which attempted to provide a full context for the desired grammatical associations of the target words, may have been treated by some participants as a translation exercise. Their preoccupation with an exact correspondence between the given Chinese contexts and the English expressions in the dictionaries may have been the result of their treatment of the task 
as a pure translation exercise.

The use of a few specific paper dictionaries may also have limited the authenticity of the study. In this technology-based new millennium, learners tend to use electronic or online dictionaries for quick and easy reference instead of relying on paper dictionaries. Even those who were used to using paper dictionaries may not have used the assigned dictionaries regularly. As Lew (2011b) points out, users tend to learn the structure and conventions of a dictionary they regularly use, and their reference skills evolve over time. Their unfamiliarity with the dictionaries used in the study may have partially contributed to the problems they encountered.

\section{Conclusion}

In this article, I have reported on the results of a study which investigated advanced Cantonese ESL learners' use of a monolingual dictionary in target language production with a full Chinese context and a partial English context. The results suggest that although a monolingual dictionary can help learners identify the correct use of a word, the usefulness of dictionary information is often constrained by the layout of the entries, the presentation of dictionary information, the learners' own preconceptions of word usage, and their deficient dictionary skills. The language in which learners' thinking processes are engaged also affects their use of dictionary information. It is suggested that lexicographers be informed of the needs and problems of dictionary users. With the advent of electronic dictionaries and online dictionaries and the increasing interest in empirical studies of electronic dictionaries (e.g. Chen 2010; Chon 2009; Dziemianko 2010), further studies using electronic or online dictionaries may be illuminating in uncovering other target language production problems facing ESL dictionary users.

\section{Acknowledgements}

The work described in this article was fully supported by City University of Hong Kong (CityU Strategic Research Grant Number: 7008005). The support of the university is acknowledged. I would also like to thank all the respondents of the survey for their participation, my research assistant for her administrative help, and the consultants in the City University Statistical Consulting Unit for their expert advice on statistical analyses.

\section{Endnotes}

1. A bilingual dictionary gives the target language translation equivalents (e.g. Chinese) of the source language (e.g. English) (Hartmann and James: 1998). A bilingualized dictionary (e.g. OALECD) contains entries which have been translated in full or in part into the target language (e.g. Chinese), but there are also definitions and examples in the source language (e.g. English) (see also Hartmann: 1994; James: 1994). 
2. An unpublished result obtained from Chan (2010)'s survey on the use of bilingualized and monolingual dictionaries by 169 Hong Kong Cantonese ESL learners showed that about 38\% of learners used Oxford Advanced Learner's Dictionary of Current English (OALDCE), $14 \%$. $20 \%$ and $13 \%$ of learners respectively used the COBUILD, LDOCE and CALD dictionaries, and the rest used others. OALDCE was not used in the present study for investigation because the definitions and usage information given in that dictionary were used as the basis of the questions in all the dictionary consultation tasks used in the present study and other related studies (e.g. Chan 2012a). Therefore, COBUILD, LDOCE and CALD were chosen.

3. No survey was specifically carried out to investigate or prove that the uses of the words necessitated by the Chinese contexts were familiar or unfamiliar to Cantonese ESL learners in Hong Kong. The claim about the words being unfamiliar was purely made based on the experience of the researcher, who has been teaching English and/or linguistics at different local tertiary institutions for about 20 years.

4. It may be argued that the introspective questionnaires were strictly speaking not introspective, as the participants had to complete one questionnaire after finishing each search. The term was used in this article because the questionnaires were done during the implementation of the tasks, so the effects of information distortion or forgetting were minimized. Given that the self-reports were written ones, there was, to the author's knowledge, no better means of obtaining truly introspective feedback other than what was done in the task.

5. Because the results presented in this section were a brief summary of a huge amount of data collected from the study, the actual tables showing the detailed numerical results are not included in this article to save space.

6. In this article, no attempt was made to report all the think-aloud data collected from the study, as a tremendously huge amount of data was generated when the participants recorded the whole of their thinking processes, some of which was not significant enough for reporting. Only the data which generated the insights raised in the article will be included.

7. The introspective quotes included in this article are all reported verbatim from the written reports provided by the participants in the group, as they were required to complete the questionnaires in written English. On the other hand, most of the think-aloud reports and the interview transcriptions are only the author's closest translations of the participants' responses in idiomatic English, as the majority of the participants chose to speak in Cantonese or a mixed-code of Cantonese and English in making the think-aloud recordings and in doing the interview. Where the participants chose to speak in only English, the quotes are also reported verbatim.

\section{References}

\section{Dictionaries}

Cambridge Advanced Learner's Dictionary. Good, M. (Ed.). 2008. Cambridge Advanced Learner's Dictionary. 3rd edition. Cambridge: Cambridge University Press.

Collins COBUILD Advanced Dictionary. Sinclair, J. (Ed.). 2009. Collins COBUILD Advanced Dictionary. 6th edition. Boston, MA: Heinle Cengage Learning.

Longman Dictionary of Contemporary English. Fox, C. and R. Combley (Eds.). 2009. Longman Dictionary of Contemporary English. 5th edition. Harlow: Pearson Longman. 


\section{Other Literature}

Abecassis, M. 2007. Is Lexicography Making Progress? On Dictionary Use and Language Learners' Needs. Lexikos 17: 247-258.

Adamska-Sałaciak, A. 2010. Why We Need Bilingual Learners' Dictionaries. Kernerman, I. and P. Bogaards (Eds.). 2010. English Learners' Dictionaries at the DSNA 2009: 121-137. Tel Aviv: K Dictionaries.

Atkins, B.T.S. and K. Varantola. 1997. Monitoring Dictionary Use. International Journal of Lexicography 10(1): 1-45.

Atkins, B.T.S. and K. Varantola. 1998. Language Learners Using Dictionaries: The Final Report on the EURALEX/AILA Research Project on Dictionary Use. Atkins, B.T.S. (Ed.). 1998. Using Dictionaries. Studies of Dictionary Use by Language Learners and Translators. Lexicographica Series Maior 88: 21-81. Tübingen: Max Niemeyer.

Battenburg, J.D. 1991. English Monolingual Learners' Dictionaries. A User-oriented Study. Tübingen: Lexicographica. Series Maior 39. Tübingen: Max Niemeyer.

Baxter, J. 1980. The Dictionary and Vocabulary Behavior: A Single Word or a Handful? TESOL Quarterly 14(3): 325-336.

Béjoint, H. 1981. The Foreign Student's Use of Monolingual English Dictionaries: A Study of Language Needs and Reference Skills. Applied Linguistics 2(3): 207-222.

Bhela, B. 1999. Native Language Interference in Learning a Second Language: Exploratory Case Studies of Native Language Interference with Target Language Usage. International Education Journal 1(1): 22-31.

Bogaards, P. and W.A. van der Kloot. 2002. Verb constructions in learners' dictionaries. Braasch, A. and C. Povslen (Eds.). 2002. Proceedings of the Tenth EURALEX International Congress, EURALEX 2002, Copenhagen, Denmark, August 13-17, 2002. Vol. II: 747-757. Euralex 2002, Copenhagen.

Bunton, D. 1989. Common English Errors in Hong Kong. Hong Kong: Longman.

Bunton, D. 1994. Common Social English Errors in Hong Kong: A Guide to Polite English. Hong Kong: Longman.

Carduner, J. 2003. Productive Dictionary Skills Training: What do Language Learners Find Useful? Language Learning Journal 28(1): 70-76.

Chan, A.Y.W. 2004a. Noun Phrases in Chinese and English: A study of English Structural Problems Encountered by Chinese ESL Students in Hong Kong. Language, Culture and Curriculum 17(1): 33-47.

Chan, A.Y.W. 2004b. Syntactic Transfer: Evidence from the Interlanguage of Hong Kong Chinese ESL Learners. The Modern Language Journal 88(1): 56-74.

Chan, A.Y.W. 2005. Tactics Employed and Problems Encountered by University English majors in Hong Kong in Using a Dictionary. Applied Language Learning 15(1\&2): 1-28.

Chan, A.Y.W. 2010. Toward a Taxonomy of Written Errors: Investigation into the Written Errors of Hong Kong Cantonese ESL Learners. TESOL Quarterly 44(2): 295-319.

Chan, A.Y.W. 2011. Bilingualized or Monolingual Dictionaries? Preferences and Practices of Advanced ESL Learners in Hong Kong. Language, Culture and Curriculum 24(1): 1-21.

Chan, A.Y.W. 2012a. The Use of a Monolingual Dictionary for Meaning Determination by Advanced Cantonese ESL Learners in Hong Kong. Applied Linguistics 33(2): 115-140. 
Chan, A.Y.W. 2012b. Cantonese ESL Learners' Use of Grammatical Information in a Monolingual Dictionary for Determining the Correct Use of a Target Word. International Journal of Lexicography 25(1): 68-94.

Chen, Y. 2010. Dictionary Use and EFL Learning. A Contrastive Study of Pocket Electronic Dictionaries and Paper Dictionaries. International Journal of Lexicography 23(3): 275-306.

Chon, Y.V. 2009. The Electronic Dictionary for Writing: A Solution or a Problem? International Journal of Lexicography 22(1): 23-54.

Cowie, A.P. 1999a. English Dictionaries for Foreign Learners: A History. Oxford: Clarendon Press.

Cowie, A.P. 1999b. Learners' dictionaries in a historical and a theoretical perspective. Herbst, T. and K. Popp (Eds.). 1999. The Perfect Learners' Dictionary (?). Lexicographica Series Maior 95: 3-13. Tübingen: Max Niemeyer Verlag.

Dziemianko, A. 2006. User-friendliness of Verb Syntax in Pedagogical Dictionaries of English. Lexicographica Series Maior 130. Tübingen: Max Niemeyer.

Dziemianko, A. 2010. Paper or Electronic? The Role of Dictionary Form in Language Reception, Production and the Retention of Meaning and Collocations. International Journal of Lexicography 23(3): 257-273.

Dziemianko, A. In press. Noun and Verb Codes in English Monolingual Dictionaries for Foreign Learners: A Study of Usefulness in the Polish Context.

Ericsson, K.A. and H.A. Simon. 1993. Protocol Analysis: Verbal Reports as Data. '93 Edition. Cambridge, MA: Bradford Books/MIT Press.

Frankenberg-Garcia, A. 2011. Beyond L1-L2 Equivalents: Where do Users of Users of English as a Foreign Language Turn for Help? International Journal of Lexicography 24(1): 97-123.

Hartmann, R.R.K. 1994. Bilingualised Versions of Learner's Dictionaries. Fremdsprachen Lehren und Lernen 23: 206-220.

Hartmann, R.R.K. and G. James. 1998. Dictionary of Lexicography. London/New York: Routledge.

Heaton, J.B. and N.D. Turton. 1987. Longman Dictionary of Common Errors. Harlow, Essex: Longman.

James, G. 1994. Towards a Typology of Bilingualized Dictionaries. James, G. (Ed.). 1994. Meeting Points in Language Studies: A Festschrift for Ma Tailai. Working Papers: 184-196. Hong Kong: Hong Kong University of Science and Technology Language Center.

Jenkins, G. 1990. English Problem Words. Hong Kong: The Commercial Press.

Kaivanpanah, S. and S.M. Alavi. 2008. The Role of Linguistic Knowledge in Word-meaning Inferencing. System 36(2): 172-195.

Kasper, G. 2000. Data Collection in Pragmatics Research. Spencer-Oatey, H. (Ed.). 2000. Culturally Speaking: Managing Rapport through Talk across Cultures: 316-369. London: Continuum.

Kernerman, I. 2007. What's So Good or Bad About Advanced EFL Dictionaries? Gottlieb, H. and J.E. Mogensen (Eds.). 2007. Dictionary Visions, Research and Practice: Selected Papers From the 12th International Symposium on Lexicography, Copenhagen, 2004: 139-145. Amsterdam/Philadelphia: John Benjamins.

Laufer, B. and T. Levitzky-Aviad. 2006. Examining the Effectiveness of 'Bilingual Dictionary Plus' - A Dictionary for Production in a Foreign Language. International Journal of Lexicography 19(2): 135-155.

Lew, R. 2004. Which Dictionary for Whom? Receptive Use of Bilingual, Monolingual and Semi-bilingual Dictionaries by Polish Learners of English. Poznań: Motivex. 
Lew, R. 2011a. Studies in Dictionary Use: Recent Developments. International Journal of Lexicography 24(1): 1-4.

Lew, R. 2011b. User Studies: Opportunities and Limitations. Akasu, K. and S. Uchida (Eds.). 2011. ASIALEX 2011 Proceedings. Lexicography: Theoretical and Practical Perspectives: 7-16. Kyoto: Asian Association for Lexicography.

Lew, R. and A. Dziemianko. 2006. A New Type of Folk-inspired Definition in English Monolingual Learners' Dictionaries and its Usefulness for Conveying Syntactic Information. International Journal of Lexicography 19(3): 225-242.

Miller, J. 2008. Teachers and Dictionaries in Australia: Is There a Need to Train the Trainers? TESOL in Context 17(2) : 11-19.

Nesi, H. and P. Meara. 1994. Patterns of Misinterpretation in the Productive Use of EFL Dictionary Definitions. System 22(1): 1-15.

Summers, D. 1988. The Role of Dictionaries in Language Learning. Carter, R. and M. McCarthy (Eds.). 1988. Vocabulary and Language Teaching: 111-125. London: Longman.

Swanepoel, P. 2000. Providing Lexicographic Support for SL Vocabulary Acquisition: What Kind, under What Conditions, for Whom and Why? Heid, U., S. Evert, E. Lehmann and C. Rohrer (Eds.). 2000. Proceedings of the Ninth EURALEX International Congress, EURALEX 2000, Stuttgart, Germany, August 8th-12th, 2000: 403-418. Stuttgart: Universität Stuttgart, Institut für Maschinelle Sprachverarbeitung.

Tono, Y. 2001. Research on Dictionary Use in the Context of Foreign Language Learning: Focus on Reading Comprehension. Lexicographica. Series Maior 106. Tübingen: Max Niemeyer.

Van Weijen, D., H. van den Bergh, G. Rijlaarsdam and T. Sanders. 2009. L1 Use During L2 Writing: An Empirical Study of a Complex Phenomenon. Journal of Second Language Writing $18(4): 235-250$. 
Appendix A: Sentences used in Sentence Completion Task

1. 我不想草率下決定.

(rush): I don't want to rush into a decision.

2. 警方會控告他謀殺.

(charge): The police will murder. charge him with

3. 我和他擦身而過,但他看不到我.

(brush): He brushed past me, but he didn't see me.

4. 高價使很多顧客卻步.

(frighten): The high prices frightened off many customers.

5. 他騙她簽合約.

(deceive): $\mathrm{He}$ contract. deceived him into signing the

6. 我的耐性是有一個限度.

(limit): There is a limit to my patience

7. 這道菜你可以用牛油代替油

(substitute): You can substitute butter for oil for this dish.

8. 這是一個戰爭死難者的紀念碑.

(monument): This is a monument to the people killed in war.

9. 我們超越了去年的銷售額.

(improve): We improved on last year's sales.

10. 他們對生孩子不抱任何希望.

(despair (verb)): They children. 
Appendix B: Sentence Construction Task

1. (little) (knowledge) (linguistics)

2. (what) (reason) (reject) (proposal)?

3. (class) (comprise) (only French students)

4. (go to) (restaurant) (opposite) (cinema)

5. (feel) (guilty) (leave the children alone)

6. (the doctor) (cure) (him) (his illness)

7. (anticipate) (see him) (in the library) (tomorrow)

8. (inform) (me) (the latest news)

9. (John) (befriend) (Mary) (when she was lonely)

10. (he) (assist) (murder) (her husband) 